\title{
LA LAPIDACIÓN COMO CASTIGO DE LAS RELACIONES SEXUALES NO LEGALES (ZINĀ) EN EL SENO \\ DE LA ESCUELA MĀLIKÍ: DOCTRINA, PRÁCTICA LEGAL Y ACTITUDES INDIVIDUALES FRENTE AL DELITO (SS. XI Y XII) ${ }^{1}$
}

\author{
DELFINA SERRANo RuANO \\ Instituto de Filología, CSIC, Madrid
}

En la doctrina legal islámica se aplica el término zinā a la relación sexual entre un hombre y una mujer fuera del seno del matrimonio o del concubinato legal. Esta conducta es considerada un delito de tipo hadd, es decir, un acto que atenta contra los «derechos de Dios»-dicho de otra manera, que excede los límites establecidos por el Legislador-y que ha sido prohibido o sancionado con castigos determinados en el Corán o en la sunna o Tradición profética ${ }^{2}$. El castigo de zinā consiste en la lapidación para los acusados que son muhsan (adulto, libre y musulmán que ha disfrutado de relaciones sexuales lícitas en el seno del matrimonio) y en 100 latigazos y el destierro durante un año para los no muḥsan (50 latigazos y seis meses de destierro, para los esclavos) ${ }^{3}$. Para que se aplique el castigo se requiere que

${ }^{1}$ Este trabajo se ha llevado a cabo dentro del proyecto «Violencia y castigo en sociedades islámicas-premodernas (al-Andalus y el Magreb)» ref. BF 2002-00075. Agradezco a Maribel Fierro sus numerosos comentarios a versiones anteriores de este trabajo

2 Véanse $E I^{2}$, s.v. «Hadd» (B. Carra de Vaux-[J. Schacht]) y N.J. Coulson, «Regulation of sexual behaviour under traditional Islamic Law» en al-Sayyid Marsot A.L. (ed.), Society and the sexes in Medieval Islam, Malibu, 1979, 64.

${ }^{3}$ Los šāfi'íes consideran que los dimmíes también pueden ser muhșan; los hanafies y los hanbalíes exigen que los dos acusados sean muhsan para que la lapidación tenga lugar; los hanafies no imponen el destierro además de los 100 latigazos como castigo de zinā. Entre los šíi ies el concepto de zinā abarca un espectro más amplio de comportamientos sexuales y el de muhsan se restringe a la persona que en el momento de producirse el delito está casada, quedando exclúdos pues los divorciados y los viudos. Véase $E I^{2}$ s.v. «Zinā̄» [Peters, R.]. Sobre el concepto de iḥsān en la escuela mālikí véase al-Burzulī,

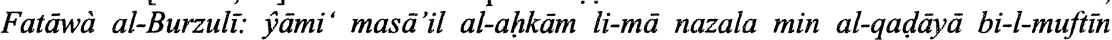
wa-l-hukkām (ed. al-Habīb al-Hīla, M.), Beirut, 2002, VI, 149. Mālik era partidario de desterrar al hombre pero no a la mujer y tampoco al esclavo - aunque también se transmitió lo contrario, es decir, que el destierro tuviera lugar independientemente del género y de la condición de libre o esclavo - y que el desterrado fuera encarcelado en el lugar en el que sufriera destierro. Véase Ibn 'Abd al-Barr, Al-Istidkār al-yāmi ' li-madāhib fuqahā" al-amșār wa-'ulamā' al-aqțār, Damasco, 1993, XXIX, 53-54.

Al-Qanțara XXVI, 2 (2005) 449-473 
los acusados hayan actuado por voluntad propia, por tanto, no hay castigo cuando ha existido una violación.

La lapidación como castigo de zinā no aparece en el Corán sino en la sunna ${ }^{4}$. Esta circunstancia no ha dejado de crear problemas de «legitimidad» para el castigo hasta hoy en día ${ }^{5}$, asunto sobre el que volveré más adelante. El delito de zinā queda probado con la declaración de cuatro testigos varones íntegros ( 'adāla) que hayan presenciado el acto de la penetración, al que suele aludirse con la expresión «como el pincel de antimonio $(k u h l)$ penetrando en el estuche de antimonio», o con la confesión del acusado ${ }^{6}$. No se admiten pruebas circunstanciales, con excepción de los mālikíes para los cuales el embarazo de una mujer que no tiene marido ni dueño legal puede imponer el hadd ${ }^{7}$. Los mālikíes, sin embargo, aceptan la doctrina de al-walad li-l-firās (literalmente, «la descendencia pertenece al lecho matrimonial»). Según esta doctrina, el marido de la madre o el dueño de la concubina es considerado padre legítimo del hijo que ella haya dado a luz, admitiéndose una duración legal del embarazo que va desde seis meses

4 Véase Ibn Abī Zayd al-Qayrawānī, al-Nawādir wa-l-ziyādāt 'alà mā fî l-Mudawwana min gayri-hā min al-ummahāt (ed. Haŷŷī, M.), Beirut, Dār al-Garb al-Islāmī, 1999, XIV, 231-32. Véase también Burton, J., "Law and exegesis: the penalty for adultery in Islam» en Hawting, G.R. y Shareef, A-K. A. (eds.), Approaches to the Qur'än, Londres, 1993, 269-84. J. Schacht sostiene que el castigo se basa en decisiones tomadas por los califas ortodoxos que luego trataron de justificar recurriendo a hadices proféticos; véase Cambridge Encyclopedia of Islam, II, parte VIII, capítulo 4, «Law and justice», p. 3, online www.fordham.edu/halsall/med/schacht.html.

5 Véase a título ilustrativo la página web de la asociación islámica española «Yama'a islámica de al-Andalus»: www.islamyalandalus.org/ene03/lapidación.htm. Esta podría ser una de las razones por las cuales, cuando en 1973 se introdujo el delito de zinā en el código penal libio, la lapidación quedó excluida como castigo en favor del de 100 latigazos y el encarcelamiento. Véase Coulson, N.J., art. cit., 64-5 y Mayer, A.E., «Libyan Legislation in Defense of Arabo-Islamic Sexual mores», American Journal of Comparative Law, 27 (1979). En Pakistán se produjo una situación similar. Véase Peters, R., Crime and Punishment in Islamic Law: Theory and Practice from the 16th to the 21st century, Cambridge University Press (en prensa), capítulo 5, sección, 1.3.2. Doy las gracias al autor por permitirme consultar su libro antes de su publicación definitiva.

${ }^{6}$ Si dos testigos declaran haber visto a un hombre y una mujer bajo un manto o dan testimonio de que ambos vieron que los pies de la mujer estaban en el cuello del hombre o si un hombre afirma que ha visto a otro hombre sobre el vientre de su mujer, los acusados pueden ser sometidos a un castigo discrecional, pero no al hadd. Véase Ibn Rušd al-Ŷadd, al-Bayān wa-l-tahsīl wa-l-šarh wa-l-tawŷìh wa-l-ta 'lìl fì masã'il al-Mustajraŷa, ed. Haŷŷi, M., Beirut, 1984, XVI, 323-24 y 356.

7 Véase Ibn 'Abd al-Barr, Istị̂kār, XXIV, 64-6; Abū Bakr Ibn al-'Arabī, Kitāb al-Qabas fí šarh al-Muwatta', Beirut, 1992, III, 1011 y Averroes, Bidāyat al-muŷtahid, El Cairo, 1960, II, 433-40. 
hasta cinco años ${ }^{8}$. Esta doctrina rige incluso si el marido, una vez formalizado el contrato entre las partes, repudia a su esposa antes de haber consumado el matrimonio con ella y luego ella resulta embaraza$\mathrm{da}$, a menos que sea evidente que la mujer miente, o que el marido pronuncie el juramento li 'ān para rechazar la paternidad ${ }^{9}$.

Las declaraciones de los testigos no pueden contradecirse entre sí. El falso testimonio de zinā es considerado firya o qadf (calumnia) y es castigado con ochenta latigazos. Si alguien da testimonio de zinā y se desdice una vez que se ha aplicado una sentencia de lapidación contra el acusado, tendrá que pagar la mitad de su precio de sangre ${ }^{10}$. Se permite al acusado retirar su confesión en cualquier momento ${ }^{11}$.

El castigo puede ser evitado cuando existe duda (šubha), es decir, semejanza entre el acto que ha sido cometido y otro legal, y por tanto, se presume que el acusado ha actuado de buena fe ${ }^{12}$.

Excepto en los delitos de calumnia, se recomienda al cadí que sugiera al acusado que retire su confesión y se considera más meritorio ocultar delitos que puedan ser castigados con hadd que ponerlos en evidencia ${ }^{13}$.

Cuando, a pesar de todas las posibilidades de evitarlo que recoge la doctrina legal, el castigo se impone, las piedras han de ser lanzadas por un grupo de personas. Si la sentencia se ha basado en el testimonio de cuatro testigos, éstos deben participar en el lanzamiento de las piedras, al igual que el sultán o su representante, el cadí. Las piedras han de ser de un tamaño mediano, que puedan ser abarcadas por la mano, pues si fueran muy pequeñas la lapidación duraría mucho tiempo y demasiado poco si fueran muy grandes ${ }^{14}$. Respecto al lugar en el

${ }^{8}$ Sobre la cual véase Ibn Rušd al-Ŷadd, Bayān, VI, 417; al-Burzulī, Fatāwà, II, 470 y Rubin, U., «'Al-walad li-l-firäsh'. On the Islamic campaign against Zinā», Studia Islamica 78 (1993), 5-26.

9 Véase Ibn Rušd, Bayān, IV, 428-29. Sobre el li ‘ān véase infra.

10 Véase Ibn Rušd al-Ŷadd, Bayān, XVI, 349-50.

11 Incluso si ya se ha aplicado parte de la pena. Lo mismo sucede con la confesión de haber consumido alcohol. Véase Ibn 'Abd al-Barr, Istidkār, XXIV, 96 y al-Burzulī, Fatãwà, VI, 149. Existe unanimidad en que si la persona que confiesa tiene una explicación plausible para retirar su denuncia, se le aceptará y el hadd quedará anulado. Ibn al-Qāsim, Ibn Wahb e Ibn 'Abd al-Hakam eran partidarios de aceptar la retractación y anular el hadd aunque el acusado no aportara excusa alguna al respecto. Véase Ibn Abi Zayd al-Qayrawānī, Nawādir, XIV, 248.

12 Véase B. Carra de Vaux y J. Schacht, art. cit. y R. Peters, art. cit.

13 Véase $E P^{2}$, s.v. «Hadd» (Carra de Vaux, B.-[Schacht, J.]).

14 Véase Peters, R., Crime and Punishment, capítulo 1, sección 1.4.11.2. 
que ha de ejecutarse el castigo, en el famoso hadiz de la lapidación de Mā'iz, sobre el cual volveré más adelante, consta que el apedreamiento tuvo lugar en el oratorio musallà [de Medina] ${ }^{15}$. En la doctrina legal clásica hay acuerdo en que no se ha de enterrar ni atar al hombre, pero hay discrepancia con respecto a la mujer ${ }^{16}$. Si se les entierra a ambos juntos para aplicar la pena, tendrán derecho, según otro hadiz, a que uno de ellos se recline sobre el otro para protegerle de las piedras ${ }^{17}$. Hay acuerdo en que un grupo de creyentes debe presenciar la aplicación del castigo, aunque se discrepa sobre si debe ser un grupo $o$ dos ${ }^{18}$. Quienes ejecutan el castigo han de ponerse en fila para lanzar las piedras, de forma que no terminen lanzándoselas entre sí ${ }^{19}$. Según algunos hadices del Profeta, quienes ejecutan la pena habrán de realizar las oraciones fúnebres por el lapidado ${ }^{20}$. La muerte puede ser causada por lesiones en el cerebro, asfixia $u$ otros daños físicos. Como una persona puede soportar golpes fuertes sin perder el conocimiento, la lapidación suele producir una muerte lenta con un sufrimiento para la víctima muy superior al que es necesario para acabar con su vida.

Existen tradiciones en las que el Profeta, 'Umar b. al-Jațāāb y 'Alī b. Abī Tâalib aparecen aplicando penas de lapidación ${ }^{21}$. Las referencias en épocas posteriores son escasas ${ }^{22}$ de forma que es lícito pensar que este tipo de castigo apenas volvió a aplicarse ${ }^{23}$, situación que como se sabe, ha cambiado en las últimas décadas al haber introduci-

15 Véase Ibn al-'Arabī, Qabas, III, 1005.

16 Véase Ibn 'Abd al-Barr, Istidkār, XXIV, 39-41. El artículo «Radjm» en $E I^{2}$ trata del lanzamiento ritual de piedras en Minā, que simboliza el apedreamiento del diablo, pero no de la lapidación como sanción coránica.

17 Istidkār, XXIV, 31; Qabas, III, 1008. Véase también Ibn Hazm, Muhallà, El Cairo, 1928-34, XI, n. ${ }^{\circ} 2187,168$.

18 Véase al respecto Ibn Hazm, Muhallà, XI, n. ${ }^{\circ} 2221,264-65$.

19 Istidkār, XXIV, 40.

20 Véase Ibn al-'Árabī, Qabas, III, 1005-6, 1008 y 1015.

21 Véase una recopilación de las mismas en Ibn 'Abd al-Barr, Istid̄kār, Kitāb al-ḥudūd, bāb mā ŷa' a fí l-raŷm, XXIV, 7-84 e Ibn al-'Arabī, Qabas, III, 1002-9. Véase también Ibn Hazm, Muhallà, XI, n. ${ }^{\circ} 2204,233-36$.

22 Véase infra.

${ }^{23}$ Entre las comunidades mudéjares, la situación parece haber sido distinta. Véase Niremberg, D., Comunidades de violencia. La persecución de las minorías en la Edad Media, Barcelona, Ediciones Península, 2001, 183-236; Segura Urra, F., «Los mudéjares navarros y la justicia regia: cuestiones penales y peculiaridades delictivas en el siglo XIV», Anaquel de Estudios Árabes, 14 (2003), 250-52 y Roy Marín, M. J., «Aportación al estudio del delito sexual: el caso de los moros de Zaragoza en el siglo XIV» en Actas del VIII Simposio Internacional de Mudejarismo. De mudéjares a moriscos: una conversión forzada (Teruel 15-17 de septiembre de 1999), Teruel, 2002, 195-210. 
do los gobiernos de países como Irán, Pakistán, Libia, Sudán y el Norte de Nigeria, el derecho penal islámico ${ }^{24}$. Sin embargo, en las colecciones de fetuas aparecen algunos - aunque muy pocos-casos reales en los que en algún momento se planteó la posibilidad de imponer una sentencia de lapidación. La mayoría de estos casos surgen cuando no se respeta el período de espera legal tras un repudio o cuando el marido retoma a la mujer a la que ha repudiado definitivamente sin esperar a que ella vuelva a serle lícita mediante la consumación de un matrimonio con otro hombre. También se incurre en el delito de fornicación cuando la mujer cuyo marido está ausente vuelve a casarse sin haber conseguido previamente la separación judicial de su primer marido o sin haberse cerciorado de que su primer marido la ha repudiado o ha muerto ${ }^{25}$. En ellos se suele dar a los esposos la posibilidad de alegar ignorancia y, por tanto, crear «duda» (̌subha) de que los acusados pensaron que su acción era lícita. A estos casos hay que sumar otros en los que hay una acusación de violación ${ }^{26}$. El relato, sin embargo, suele detenerse en el momento en que los muftíes consejeros del cadí emiten su dictamen, sin que sepamos por cual de ellos se decidió el juez. No obstante sus limitaciones, éstas son las únicas referencias con las que contamos para estudiar la actitud aparentemente contradictoria de los juristas, que por una parte afirman que el castigo de lapidación se encuentra en vigor, pero por otra insisten en

\footnotetext{
24 Véase Peters, R., «The Islamization of criminal law. A comparative analysis», Die Welt des Islams, 34 (1994), 246-74; idem, «The Judiciary and the re-Islamisation of Criminal Law in Northern Nigeria: The Safiyyatu Hussaini case», en Masud, M.Kh., Peters, R. y Powers, D. (eds.), Dispensing Justice in Muslim Courts: Qadis, Procedures, and Judgments, Studies in Islamic Law and Society, Leiden, Brill, en prensa; Sidahmed, A., «Problems in contemporary applications of Islamic criminal sanctions: The penalty of adultery in relation to women», British Journal of Middle Eastern Studies, 28/2 (2001), 187-204; Ahmad, S., «Zina and Rape under the Syariah Criminal Code (II) Bill 1993 (Kelantan)» en Ismail, R. (ed.), Hudud in Mayasia. The Issues at Stake, Kuala Lumpur, 2002 (repr. De Kuala Lumpur, 1995), 13-21.

25 Véase, por ejemplo, Bayān, V, 30-31, XVI, 317-18; Mi 'yār, II, 430-32 y III, 37-9, 41-3, 58-9, 109-10, 198-9, 399-400, 401-2; Burzuli, Fatāwà, II, 200-1, 345 y X, 361-67. Véase también Powers, D., «From Almohadism to Mālikism: The case of al-Haskūrī, the Mocking Jurist, ca. 712-716/1312-1316" en idem, Law, Society, and Culture in the Maghrib, 1300-1500, Cambridge (RU), Cambridge University Press, 2002, 53-94.

26 Véase, por ejemplo, $M i$ ' yār, IX, 573 y III, 82-3, 132 y 256. Véase también Serrano Ruano, D., «La violación en derecho mālikí: doctrina y práctica a partir de tres fetuas de los siglos X a XII d. C.», Mélanges de la Casa de Velázquez, Nouvelle Série, 33/1 (2003), 125-48 e idem, «Doctrina legal islámica sobre el delito de violación: escuela mâlikí (ss. VII-XV)» en Calero, I. (ed.), Mujeres y sociedad islámica: una visión plural (en prensa).
} 
la necesidad de respetar escrupulosamente los requisitos que impiden su puesta en práctica. Las fetuas nos hablan, además, de motivaciones para denunciar, de argumentos para condenar, de estrategias para evitar el castigo y de la práctica judicial asociada con las acusaciones de zinā.

De entre los casos que he podido documentar, he seleccionado uno que aparece en las Fatāwà de Ibn Rušd al-Ŷadd ${ }^{27}$. Es muy breve pero interesante pues, a simple vista, nos hace presagiar una sentencia de lapidación casi segura. Proporciona además un buen hilo argumental para examinar la doctrina sobre zinā de Ibn Rušd al-Ŷadd ${ }^{28}$ (450/ 1048-520/1126), uno de los juristas mālikíes más relevantes de todos los tiempos. Vivió bajo el gobierno de los almorávides, cuya legitimidad política y religiosa se basó en la aplicación de la doctrina de la escuela de Mālik, en la práctica del ŷihād o guerra santa y en el sometimiento nominal al califato "Abbäsí ${ }^{29}$. El emir almorávide "Alï b. Yūsuf nombró a Ibn Rušd cadí supremo de Córdoba en 511/1117, función de la que pidió ser relevado cuatro años después para dedicarse por entero a la redacción de sus obras. Durante este tiempo se encargó del sermón de los viernes en la mezquita aljama al tiempo que formaba parte del consejo consultivo de alfaquíes de la ciudad $(\check{s} \bar{u} r a)^{30}$. Con los almorávides actuó en varias ocasiones como una especie de muftí oficial.

El caso es el siguiente:

Un cierto juez de la zona de Almeria (ba'd al-likukkām bi-ŷihat al-Mariyya) pidió opinión a Ibn Rušd al-Ŷadd sobre el caso de una mujer que había sido denunciada ante el juez por haberse quedado embarazada a consecuencia de una re-

${ }^{27}$ Fatāwà Ibn Rušd al-ŶYadd, ed. al-Talìlī, M.T., Beirut, Dār al-Garb al-Islāmī, 1987, III, 1394-95 y 1399; idem, Masā'il Abī l-Walìd Ibn Rušd al-Ŷadd, ed. al-Taŷkānī, M. al-H., Casablanca, Dār al-afãq al-ŷadìda, 1992, II, 1241, 1243, 1246. Véase también en $M i$ yār, IV, 252 y 253 y Marín, M., Mujeres en al-Andalus, Madrid, 2000, 676-67.

28 Doctrina que he extraído de los capítulos sobre gas $b$ (usurpación y también violación), li 'ān, sanciones coránicas, matrimonio y repudio de su comentario sobre la 'Utbiyya titulado al-Bayān.

${ }^{29}$ Véase Fierro, M., «La religión» en Viguera, M.J. (coord.), El retroceso territorial de al-Andalus. Almorávides y almohades. Siglos XI al XIII, Historia de la España Musulmana Menéndez Pidal, dirigida por Jover Zamora, J.M. (=HEM), VIII-2, Madrid, 1997, $437-42$.

${ }^{30}$ Sobre su biografia y su metodología juridica véase ahora Fernández Félix, A., Cuestiones legales del Islam temprano: la 'Utbiyya y el proceso de formación de la sociedad islámica andalusí, Madrid, CSIC, 2003, 258-74. 
lación sexual ilícita (min zinā) dos veces y por haber matado a los recién nacidos. "Y fue llevada a mi presencia (rufi'at ilayya)», señala el juez peticionario y prosigue: «Era evidente que estaba embarazada y le pregunté ¿estás embarazada? a lo que ella respondió: sí, estoy embarazada, y [el hijo que espero] es de Fulano. Entonces le pregunté: ¿y cómo te has quedado embarazada de él? Ella respondió que él no había dejado de seguirla y de solicitarla hasta que la violó (akraha-hā)». Antes de proseguir con la exposición de los hechos, el peticionario se detiene para preguntar a Ibn Rušd: «¿Puede ella utilizar esta alegación ( $d a$ 'wà) en su descargo?». «Cuando ella dio a luz», continúa relatando el juez «convocó a los testigos para que dieran fe del recién nacido, reconociendo ella que era su madre. Y se trataba de una mujer muhsana». Dando por sentado que la mujer mentía y que su alegación era una calumnia ( $q a d f$ ) contra el acusado de haberla violado, el juez pregunta a Ibn Rušd: «Si el calumniado (al-maqdūf $b i$-hi) renuncia a su derecho a [que ella] sea castigada con la sanción coránica (hadd) [por calumnia], ¿queda anulada la pena?»

Ibn Rušd respondió: «A la mujer contra la cual consta lo que has mencionado es obligatorio lapidarla (al-raŷm). Pero solamente el qãdî $l$-yamã' $a$ puede emitir una sentencia de ese tipo. Elévale el caso para que él decida (yahkum) qué sentencia hay que aplicar, ya que los magistrados de las coras (hukkäm al-kuwar) ${ }^{31}$, no pueden dictar sentencia en materia de sanciones coránicas que impliquen la muerte del acusado».

Resulta difícil precisar las fechas en que tiene lugar la consulta. No parece probable que en el momento de ser consultado Ibn Rušd ocupara el cadiazgo en Córdoba pues en la petición de fetua este extremo no es mencionado, mientras que sí lo es en otros casos como puede comprobarse en las dos ediciones de sus fetuas. En ellas suele diferenciarse bien entre qādi y hăkim y entre la zona o la provincia de Almería (ŷiha, kūra) y la capital (al-hadra) ${ }^{32}$. La única sede judicial de la zona de Almería que he encontrado documentada en época almorávide es Berja. En ella se sabe que ejerció como cadí Abū Isḥāq Ibrāhim b. Muhạmmad b. Ismā'īl b. Fūrtiš hasta su muerte en 531/1136-37 33. Al menos durante el período en que Abū 'Abd Allāh Ibn Hamdīn (m. 514/1120) ocupó la judicatura suprema en Córdoba, la sede judicial de Almería dependía de Córdoba, ya que fue Ibn

31 Que es precisamente lo que era el juez que solicitó el dictamen a Ibn Rušd.

32 Véase por ejemplo Masã $i l$, II, 1284 y 1303 y la entrada correspondiente a Almería en el índice de topónimos de ambas ediciones.

33 Véase la tesis doctoral de R. El Hour, La organización juridica de los almorávides en al-Andalus, Universidad Autónoma de Madrid, 1996, I, 434-35, a quien agradezco que me haya permitido su consulta. Sobre los cadíes de la capital, Almería, véase El Hour, R., «Almería almorávide: sede de una oposición política y de un importante poder judicial», Revista del Instituto Egipcio de Estudios Islámicos en Madrid, XXXII (2000), 99-118. 
Hamdīn quien designó a Abū 'Abd Allāh Muhammad b. 'Abd al-Malik cadí de Almería ${ }^{34}$. Sin embargo, 'Abd al-Haqq Ibn 'Ațiyya, que en 529/1134 ocupó también el cadiazgo de Almería, fue nombrado directamente por el emir almorávide 'Alī b. Yūsuf, e incluso es denominado qādi l-yama 'a en la inscripción que, al parecer, conmemora la construcción de una pila de abluciones en la mezquita aljama de la ciudad ${ }^{35}$.

Como ya he señalado, a simple vista, el dictamen de Ibn Rušd lleva a pensar en una condena a muerte casi segura para la mujer. En mi opinión, se trata de un efecto buscado intencionadamente por el muftí con el fin de asegurarse no tanto de que la mujer recibiera el castigo que correspondía al delito que supuestamente había cometido sino de que su caso fuera juzgado por el cadí supremo y no por el magistrado almeriense.

Aparte de la posibilidad de acogerse a la doctrina de al-walad li-l-firāš o de presentar una alegación que produzca una presunción de inocencia en favor del acusado, hemos visto que la doctrina legal islámica impone una serie de restricciones que hacen más difícil probar un delito de tipo hadd que otro tipo de delitos. Ibn Rušd añade a todo esto una limitación de tipo jurisdiccional que convierte al cadí supremo en el único magistrado competente en materia de sanciones coránicas que impliquen la muerte del acusado, limitación ésta de la que no parece que el juez almeriense fuera consciente. Con la denominación $q \bar{a} d \bar{l}$ $l$-yamá ' $a$ creo que Ibn Rušd se refiere al magistrado que hubiera sido designado para el cadiazgo por el emir con esa titulatura y cuya sede se encontrara más próxima al lugar del proceso, no necesariamente a un magistrado con un nivel jerárquico superior al del resto de los cadíes importantes del imperio almorávide. Es decir, creo que se refiere a un juez religioso con competencias plenas, por eso utiliza $q \bar{a} d \bar{l} \bar{l} l-\hat{y} a m \bar{a}^{\prime} a$ por oposición a hukkām al-kuwar y no a qudāt al-kuwar.

Desde el punto de vista doctrinal, Ibn Rušd se limita a especificar que se trata de un caso de raŷm pues ella reconoció que el hombre que la había dejado embarazada no era su marido. Siendo ella muhșana, el castigo que le correspondía era la lapidación. Puesto que este tipo de

\footnotetext{
34 Véase El Hour, R., art. cit., 111-12.

${ }^{35}$ Véase Fórneas, J.M., «Los Banū 'Ațiyya de Granada (II), MEAH, XXVI (1977), 33-4. Sobre Almería, el más importante de los puertos comerciales de al-Andalus en el período almorávide, véase Molina, E., en Viguera, M.J. (coord.), HEM-VIII/2, 283-87.
} 
delitos sólo pueden ser juzgados por el cadí supremo se entiende que el muftí no entre a detallar la doctrina relevante; en todo caso esa necesidad surgiría más adelante, una vez que el cadí hubiera asumido el caso. Sin embargo, llama la atención que Ibn Rušd renuncie a todo afán pedagógico y no conteste a ninguna de las preguntas que le formula el mustafti: «¿le sirve a ella de algo alegar que ha sido violada? Si la víctima de una calumnia perdona a su calumniador ¿queda anulado el hadd correspondiente?» Mi impresión es que Ibn Rušd no quería proporcionar ningún tipo de argumento que pudiera servir al de Almería para actuar por su cuenta. Ibn Rušd se limita a lo esencial y crea la expectativa de que la mujer va a ser condenada a la pena máxima — una pena más severa de la que quizá había previsto el juez y las personas que habían denunciado a la mujer - para asegurarse de que el caso fuera efectivamente transferido al cadí supremo. De alguna manera, el muftí temía que el juez no siguiera sus recomendaciones o que cuando pudiera ser obligado a ello, hubiera decidido aplicar ya algún castigo.

A continuación voy a volver sobre las circunstancias del caso, tanto las que aparecen mencionadas explícitamente como las que pueden inferirse de la lectura del texto, y voy a tratar de relacionar dichas circunstancias con la doctrina legal que he expuesto al inicio de este artículo. Al hacerlo, voy a dar por supuesto que el texto de la fetua no fue resumido por el compilador, pues no veo razones para pensar que lo hiciera y además, es frecuente que los muftíes no contesten a todas las preguntas que les son formuladas. Asimismo, me remitiré a una serie de pasajes en los que se ilustra la doctrina del propio Ibn Rušd y la de otros juristas importantes. Aunque desconocemos el desarrollo judicial posterior del caso, voy a imaginar que fue efectivamente remitido al cadí supremo y voy a tratar de ponerme en su lugar y en el de los muftíes a los que el magistrado habría consultado antes de dictar sentencia.

Hemos visto que la mujer admitió que el hijo que esperaba era fruto de una relación sexual ilegal, aunque no consentida por su parte. Esta alegación no la realizó a iniciativa propia sino cuando fue interrogada por el juez ante el cual había sido denunciada. Cuando compareció ante el mismo se encontraba en un avanzado - y por tanto evidente- estado de gestación. El problema legal que se planteaba en ese momento es que, de acuerdo con la doctrina mālikí ${ }^{36}$, para que

36 Véase Bayān, XI, 234-6 y XVI, 310-2. 
una demanda de violación fuera admitida, debía realizarse de forma inmediata y a iniciativa de la mujer, a menos que tuviera testigos ${ }^{37} \mathrm{o}$ una excusa válida para no haber denunciado antes. Es evidente que la almeriense acusada de zinā pensó que la única salida que le quedaba era alegar una violación, sin saber que al hacerlo se estaba poniendo en serios apuros. El dato es interesante, en cualquier caso, pues refleja la manera en que ella pensaba que podía defenderse. No hay que descartar, de todas formas, que su declaración fuera consecuencia de la presión ejercida por sus denunciantes, o incluso de haber sido sometida a algún tipo de tortura ${ }^{38}$. Finalmente, es posible que simplemente estuviera diciendo la verdad.

Cuando la mujer da a luz, sin embargo, parece que ya ha recibido cierto asesoramiento y convoca a unos testigos para que den fe de la existencia del recién nacido y de que ella reconoce ser su madre, poniéndose de manifiesto también que se trata de una mujer muhsana.

La mujer libre no tiene que presentar testimonio del nacimiento de su hijo para que éste sea reconocido por su marido ${ }^{39}$. Así pues, si la acusada llamó a los testigos a pesar de que era una mujer libre debió de ser porque el recién nacido no tenía padre reconocido. Se trataba quizá de una mujer que, abandonada, repudiada o viuda, vivía sin la protección de su familia. No parece que se tratara de una prostituta o de una mujer de mala fama pues de haberlo sido, seguramente el $m u s$ tafti lo hubiera mencionado. En una situación así, la madre ha de reconocer a su hijo para que éste pueda ser emparentado con ella, con sus parientes varones ('așaba) y con sus mawāli, filiación que es necesario determinar para que pueda establecerse la solidaridad penal, la tutela matrimonial y la capacidad de heredarse. La fetua proporciona pues un testimonio de la vigencia en la práctica de una tendencia que Robert Brunschvig detectó a partir del estudio de obras de doctrina legal islámica y según la cual el hijo nacido de una relación ilegal o rechazado por el marido de su madre a través del juramento de

37 Véase Ibn 'Abd al-Barr, Istidikār, XXIV, 65.

38 Véanse algunos testimonios del recurso a la tortura en $M i$ ' yār, II, 286 y 308-10. Véanse también los artículos de M. Marín y Ch. Müller en esta misma sección, así como Johansen, B., "Verité et torture: ius commune et droit musulman entre le $\mathrm{X}^{\mathrm{e}}$ et le XIII siècle», en Héritier, F. (ed.), De la Violence, París, 1996, 144-46.

${ }^{39}$ La esclava, por el contrario, tiene que presentar testimonio del nacimiento de su hijo nacido de una relación sexual admitida por su dueño para ser reconocida como $\mathrm{umm}$ walad, no basta con que se presente con el niño porque podría haber cogido a un niño abandonado (laqīt); véase Ibn Rušd, Bayān, VI, 425. 
li 'ăn ${ }^{40}$, no resulta tan despegado de su familia «natural» como creían algunos expertos en derecho islámico (v.gr. G.H. Bousquet y L. Mi1liot), ni siquiera en la escuela mālikí que era entendida como la más restrictiva respecto al reconocimiento de los lazos familiares maternos ${ }^{41}$.

La llamada a los testigos se explica también por la necesidad de certificar que ella era muḥsana, es decir, que estaba o había estado casada, circunstancia de la que había que presentar prueba testimonial, no bastando la palabra de la mujer ${ }^{42}$. Es probable que alguien le hubiera advertido del error cometido al declarar que el hijo que esperaba era fruto de una violación, pues siendo ella una mujer casada, repudiada o viuda, hubiera podido atribuir la paternidad del niño a su marido según la doctrina de al-walad li-l-firāš. Que él estuviera ausente, muerto o que la hubiera repudiado no representaba un problema legal, a menos que cualquiera de estas tres circunstancias se hubiera producido más de cinco años atrás.

Una vez ante el cadí, éste volvería a interrogarla y entonces ella podría retirar su confesión inicial y presentar los hechos de esa otra manera. Antes de tomar una decisión, el cadí consultaría a varios muftíes, entre los cuales es muy probable que se contara el propio Ibn Rušd.

$\mathrm{Si}$, en caso de no ser ella viuda, el marido ausente, o el anterior marido, no hubiera querido hacerse cargo de la paternidad de este niño, habría podido recurrir al li 'ān. El li 'ān es un juramento que, en ausencia de prueba legal, da al marido la posibilidad de acusar a su mujer de adulterio y de rechazar la paternidad del hijo que ella espera, sin incurrir por ello en el delito de calumnia. Para evitar el castigo de zinã la esposa tiene que pronunciar también el juramento. Al final de este proceso, el matrimonio queda disuelto sin que el hombre pueda volver a tomar a esa mujer por esposa ${ }^{43}$.

Supongamos ahora que a la mujer no le era posible atribuir el hijo al marido porque habían pasado más de cinco años desde que su marido se ausentó, murió o la repudió, siendo esa la razón por la que

\footnotetext{
40 Sobre el cual véase infra.

${ }^{41}$ Véase Brunschvig, R., «De la filiation maternelle en droit musulman», Studia Islamica 9 (1958), 49-59, esp. 58-9.

${ }^{42}$ Véase Ibn Abī Zayd al-Qayrawānī, Nawādir, XIV, 260.

${ }^{43}$ Véase $E I^{2}$, s.v. «Li'án»» [Schacht, J.]. Sobre la manera en que ha de prestarse este juramento véase Ibn Rušd, Bayān, VI, 421 y 425.
} 
ella, según afirmaban los denunciantes, había matado a los dos hijos a los que había dado a luz anteriormente. Es también verosímil que se hubiera deshecho de ellos no por temor al castigo sino por falta de medios para criarlos. Puede ser, igualmente, que desconociera la doctrina de al-walad li-l-firāšs, como le sucedió a la protagonista de una fetua, también de época almorávide, transmitida por al-Burzulī:

El jurista Ibn al-Ḥâŷy fue consultado acerca de una mujer que llevaba repudiada más de un año y dio a luz y abandonó (tarahat) a su hijo. Ella alegó que el niño era de su marido, pero que había tenido miedo a la sanción coránica. Ibn al-Haŷŷ respondió que si ella presentaba testigos del nacimiento de su hijo, que se le diera crédito ${ }^{44}$.

La almeriense denunciada ante el juez podría haber alegado algo parecido: que el niño era de un hombre que la había repudiado o que su marido estaba ausente y que había acusado a otro hombre de haberla violado por miedo.

Ahora bien, si se demostraba que había matado a los dos recién nacidos anteriores, como alegaban quienes la denunciaron, sería ajusticiada según la doctrina que se transmite en el siguiente pasaje del Bayān de Ibn Rušd:

Mālik fue preguntado sobre si la prostituta (al-mar'a tafŷur) que se queda embarazada y cuando da a luz arroja al recién nacido a un pozo, ha de ser ajusticiada por ello, o no. Y respondió: «depende de si lo arrojó a un lugar donde perecería [con toda seguridad] (mahlak) como el pozo de agua abundante o el mar, y efectivamente muere. En ese caso, lo más justo es que sea ajusticiada. Y si es ajusticiada, lo merece. [Dijo Ašhab] ${ }^{45}$ : «Parece que él [Mālik] se inclinaba por que ella fuera ajusticiada y lo veía conveniente». Așbag dijo algo similar: «esta [mujer] mata intencionadamente y es como si hubiera asesinado [al bebé] degollándolo; ahogar[lo] es lo mismo». Ibn al-Qāsim introdujo la siguiente matización: «pero si se tratara de un lugar como el pozo seco del que es posible que el [recién nacido] sea rescatado, o un lugar parecido, que no sea ajusticiada, a menos que el pozo, aunque seco, sea muy profundo y no se pueda acceder a él ni descender [a su fondo], en cuyo caso, veo conveniente que sea ajusticiada».

44 Véase al-Burzulī: Fatāwà, VI, 146. Ibn 'Abd al-Barr recoge en su Istid̄kār, XXIV, 73-6 hadices que apuntan a la existencia de un desajuste entre la duración legalmente admitida del embarazo y la percepción que la gente tenía al respecto. Mālik.

${ }^{5}$ Esta cuestión se encuentra en el epígrafe: $\min$ sama $\bar{a}^{\prime} A$ šhab wa-Ibn Nāfi ' 'an 
Ibn Rušd comenta que este caso se asimila al del homicidio intencionado entre padres e hijos, mientras que el homicidio accidental se salda con el precio de sangre ${ }^{46}$.

En el hipotético caso de que la mujer hubiera permanecido sin marido durante más de cinco años, le quedaban aún otros argumentos por utilizar como, por ejemplo, que tenía un sueño muy profundo y que alguien debía de haber yacido con ella mientras dormía ${ }^{47}$. No obstante, Ibn Rušd era muy estricto con respecto a que se realizaran alegaciones en este sentido a la ligera, como se desprende del siguiente pasaje:

En el Kitäb al-ruhūn (capítulo sobre las prendas) [de la 'Utbiyya] se transmite el caso de una mujer cuyo marido se ausentó durante un período de diez años o más, y cuando regresó, encontró que ella había tenido varios hijos. Él negó que fueran suyos, a lo cual la mujer replicó: «Son tuyos, viniste a mí en secreto». [Ibn al-Qāsim] dijo: «sólo quedará eximido de la paternidad del hijo de ella y del hadd [por calumnia] si pronuncia el li'ān».

Ibn Rušd comenta esta cuestión afirmando que, previamente, la alegación de ella ha resultar verosímil, pero si la ausencia de él fuera conocida mediante el testimonio de testigos íntegros y se supiera que ha estado en una tierra lejana desde la que resultaba imposible haber engendrado hijos en el lugar [en el que vivía su mujer y] al que había regresado [al cabo de los diez años], si él negara la paternidad de esos hijos, que no le sean atribuidos y que ella sea castigada con el hadd pues es evidente que ella presentó una alegación falsa ${ }^{48}$.

Este texto pone de relieve los límites de la protección que la doctrina sobre de al-walad li-l-firāš podía otorgar a la vida de una mujer que se ha quedado embarazada de un hombre que no es su marido.

El método de razonamiento legal de Ibn Rušd le impide aceptar alegaciones inverosímiles como medio de defensa frente a la acusación de zināa, pero también le lleva a rechazar el castigo en un supuesto en el que otro jurista anterior lo había considerado conveniente, como sucede en el siguiente pasaje ${ }^{49}$ :

46 Bayān XV, Kitāb al-diyāt al-awwal, 470.

47 Véase Ibn 'Abd al-Barr, Istiḍkār, VII, 509-11; al-Burzulī, Fatāwà, VI, 149. En Arabia Saudí, actualmente, algunos jueces aceptan el embarazo como prueba de zinā. Sin embargo, para evitar el castigo es suficiente con que la mujer alegue haber sido violada, o embarazada mientras dormía, sin necesidad de probar dicha alegación. Véase Peters, R., Crime and Punishment, capítulo 5, sección 1.2.

48 Bayān, VI, 413-14.

49 Bayān, VI, 425-26 
Se le preguntó a Saḥnūn por un hombre que se negó a reconocer al hijo del que estaba embarazada su mujer (yantafí min haml imra'ati-hi) y pronunció contra ella el $l i$ 'àn, pero ella se negó a pronunciarlo [a su vez]. Sin embargo, no era posible lapidarla hasta que diera a luz. Más tarde el marido se desdijo (yukadd nafsa-hu) antes de que ella diera a luz y después de que ella se hubiera negado a jurar. ¿Tiene él derecho a retomarla (hal la-hu 'alay-hā ray' 'a)? Y ¿pueden heredarse el uno al otro?

Respondió: el hecho de que él pronunciara el juramento de $l i$ 'ān contra ella y el hecho de que ella se negara a pronunciarlo a su vez rompe el vínculo conyugal ( 'ișma) de forma que ni él la hereda ni ella le hereda, y cuando ella dé a luz, que sea lapidada.

A lo cual el jurista cordobés objeta lo siguiente:

Esta solución no tiene base en las fuentes (laysat 'alà l-ușūl) y tampoco en la opinión según la cual el vínculo queda roto cuando el marido completa el li 'ān, sin que puedan heredarse el uno al otro, tanto si ella se niega a jurar como si no. Lo correcto ( $a l$-sahịh) es el precedente establecido ( $m \bar{a}$ maḍa) en la sección «tuvo hambre» $(\hat{y} \bar{a} a)^{50}$ a partir de la audición de Yahyà. Según dicho precedente, el vínculo conyugal entre ambos permanece y ambos se heredan [y por tanto, ella no es castigada]. La afirmación de Sạ̣nūn según la cual la negativa de ella a jurar tras haber él pronunciado el $l i$ 'ãn cortaba el vínculo conyugal entre ambos diverge de las fuentes (järîy 'an al-ușūl).

Por otra parte, Ibn Rušd sostenía que no se puede negar la paternidad de un hijo sin pasar por el procedimiento del $l i$ ' $a n n$. Al-Burzulī, que se manifiesta seguidor de esta doctrina de Ibn Rušd, cuenta que

Ibn al-Qașsār ${ }^{51}$ opinaba que si el marido niega ser el padre del hijo que está esperando su mujer, pero no la acusa de zinā y después se niega a jurar, no se le obligará [a nada] porque él no la calumnió, pues cabe la posibilidad de que el niño hubiera sido concebido a partir de una unión sexual por equivocación ('an waț ' galaț) o a consecuencia de una violación.

Al-Burzulī señala que esta postura se encuentra en divergencia con el sentido literal de lo que aparece en la Mudawwana.

50 Se refiere a Bayān, XVI, 324-25: wa-min kitāb ŷā'a fa-bā'a imra'ata-hu (del capítulo «tuvo hambre y vendió a su mujer»). Sobre esta circunstancia como eximente del castigo de zinā véase infra.

${ }_{51}$ Abū l-Hasan 'Alī b. Ahmad b. Ismā'īl al-Bagdādī, alfaquí mālikí m. 398/1008. Véase 'Iyāọ b. Mūsà, Tartīb al-madārik wa-taqrīb al-masālik, ed. Bencherifa, M. et al., Rabat, 1403/1983, VI, 207. 
Yo dictaminé, igual que había hecho Ibn Rušd, de acuerdo con dicho sentido literal, sin tener en cuenta la máxima de al-Qașșār.

Aparte de ser legalmente lícita, esta manera de proceder garantizaba la preservación del orden social y de la moral pública:

Se contó de al-Ša ${ }^{a} \mathbf{b i}^{52}$, que lo tenía de al-Išbīlī ${ }^{53}$, que quien reconoce haber cohabitado [con una mujer con la que está o ha estado casado] y niega el hijo que ella espera sin alegar [que la repudió o que la vendió si era esclava y que el embarazo se produjo después de que ella hubiera completado] el período de espera legal para determinar si su matriz estaba vacía (istibrä́), que sea encarcelado de forma perpetua hasta que reconozca al hijo, porque si el ejemplo de este [hombre] prevaleciera por encima de la norma según la cual los hijos son atribuidos [a los maridos de sus madres], abundaría el libertinaje entre la gente común $(\text { al-'awāmm })^{54}$.

En otra ocasión, evocando el principio según el cual «las sanciones coránicas se rechazan en casos dudosos (al-hudüd tudra' bi-l-šubuhāt), Ibn Rušd llega a afirmar que si un hombre vende a su mujer a otro hombre porque tiene hambre, el hambre constituye «duda» (šub$h a$ ), pues «qué šubha hay más fuerte que el hambre, por cuya causa Dios permitió comer carroña, sangre (reses no degolladas de acuerdo con lo establecido) y la carne del cerdo» ${ }^{55}$.

Volviendo al análisis de las circunstancias que dieron lugar a la petición de fetua formulada por el juez almeriense, no es posible determinar si los denunciantes fueron individuos - vecinos o familiares de la mujer, quizá ${ }^{56}$ - que actuaban por interés particular, si formaban parte de una especie de policía de costumbres voluntaria o si ejer-

52 Abū 1-Muțarrif 'Abd al-Raḥmān b. Qāsim al-Ša'bī, jurista malagueño (m. 499/1106), autor de una recopilación de casos judiciales conocida con el título de al-Ahkām, ed. al-Halawī, Ș., Beirut, 1992.

${ }_{33}$ Abū 'Umar Ahmad b. 'Abd al-Malik b. Hāšim conocido como Ibn al-Makwī. Muftí cordobés con el que al-Š̉a bĩ aprendió fiqh (m. 401/1010). Véase 'Iyāḍ, Tartīb, VII, 123-35; Cano, P., «El jurista sevillano Ibn al-Makwī (s. X-XI), Philologia Hispalensis, 7 (1992), 123-40 y Peña, S., «Ibn al-Makwì», en Marín, M. (ed.), Estudios Onomástico-Biográficos de al-Andalus, VI, Madrid, 1994, 353-83.

54 Al-Burzulī, Fatāwà, II, 469. Véase también al-Ša'bī, Aḥkām, 387.

55 Bayān, XVI, 324-25. Véase también Mi yār, IX, 573, fetua de al-Qābisī e Ibn Abī Zayd al-Qayrawān̄i, al-Nawādir, ed. Amin Boukhobza, M.M., Beirut, Dār al-garb al-islāmī, 1999, X, 265.

${ }^{56}$ Por ejemplo en $M i{ }^{4} y a \bar{r}$, IX, 573 al-Wanšarīsī recoge una fetua de al-Qābisī acerca de una muchacha que se ausentó durante tres días y cuando apareció, fue su hermana quien la llevó ante el juez. 
cían la hisba por designación de la autoridad. Esta diferencia, como vamos a ver, era muy importante para Ibn Rušd, quien en más de una ocasión critica abiertamente a los que denuncian delitos sexuales. En su Bayān transmite un pasaje según el cual

\footnotetext{
Aṣbag dijo: oí a Ibn al-Qāsim contar que cuatro hombres agarraron a otro, lo llevaron ante el sultán y dieron testimonio contra él de que había cometido zinā. Ibn al-Qāsim opinaba que este testimonio no era lícito y que habían incurrido en calumnia.

Ibn Rušd señala que ese testimonio no es lícito porque no era su obligación atraparlo y llevarlo agarrado ante el sultán; mejor dicho, afirma, «es reprobable que lo hicieran porque al ser humano se le ordenó que se protegiera (al-sitr) a sí mismo y a los demás. El Enviado de Dios - Dios lo bendiga y salve- dijo: a quien afecte algo de esta abominación ( $q \bar{a} \underline{d}$ ūra) que se cubra con el manto de Dios ${ }^{57}$, pero a quien nos muestre su cara (man yubdi la-nā safhata-hu), le aplicaremos [lo que prescribe] el Libro de Dios» ${ }^{58}$. [En otra ocasión, el Profeta] dijo a [un hombre de la tribu de Aslam llamado] Hazzäl: « ¡Oh Hazzäl! Si lo hubieras cubierto con tu manto (bi-ridā' $i-k a$ ) habría sido lo mejor para ti».
}

Según M. Haŷŷī, editor del Bayān de Ibn Rušd, este personaje llamado Hazzāl a quien el Profeta dirigió las palabras que preceden, era Ibn Diyāb b. Yazīd al-Aslamī ${ }^{59}$. El hadiz es transmitido por Mālik en su Muwatta' y por tanto entiendo que ha de ser leído en conexión directa con el hadiz inmediatamente anterior, según el cual un hombre de la tribu de Aslam fue a ver a Abū Bakr al-Siddīq y le dijo que había cometido zinā, a lo cual Abū Bakr respondió: «¿se lo has dicho a alguien más?» El hombre respondió que no y Abū Bakr le aconsejó «taparlo con el manto de Dios, pues Dios acepta el arrepentimiento de sus siervos». Pero el hombre no se quedó tranquilo y se dirigió a 'Umar b. al-Jattāa a quien hizo la misma confidencia. 'Umar le respondió de la misma manera que Abū Bakr. No satisfecho con esta respuesta, el hombre se dirigió entonces al Profeta y por tres veces confesó ante él que había cometido zinā. El Profeta se apartó de él otras tantas veces, pero a la cuarta ordenó que trajeran a alguien de su familia para preguntarle si estaba aquejado de alguna enfermedad mental, pero afirmaron que estaba sano. Después el Profeta preguntó si era virgen o si había estado ya casado, a lo cual

57 Este hadiz también lo cita al-Burzulī, Fatāwà, II, 471.

58 Véase Bayān, XVI, 335 n. 172.

59 Véase Bayān, XVI, 335 n. 173. 
le respondieron que lo segundo. El Profeta ordenó entonces que fuera lapidado ${ }^{60}$.

Parece, pues, que el Hazzāl del segundo hadiz y el hombre de la tribu de Aslam del primer hadiz son la misma persona. Parece ser también que Hazzāl es el mismo personaje al que en otras tradiciones se alude con el nombre de Mā'iz. ${ }^{61}$. El hadiz relativo a la lapidación de Mā'iz es muy conocido y suele citarse como fundamento textual del comportamiento que ha de seguir el juez ante alguien que confiesa haber cometido zinā. De esta tradición se transmiten varias versiones que pueden resumirse como sigue: Un musulmán, Mā'iz, se acerca al Profeta y le dice que ha tenido relaciones sexuales ilícitas con una mujer. Entonces el Profeta se aparta de él. El hombre vuelve a insistir en su afirmación y el Profeta, de nuevo, se aparta de él. Este proceso se repite de forma que Mã'iz afirma cuatro veces haber cometido zinā. El Profeta le pregunta si no será que se encuentra perturbado mentalmente, o que ha bebido, pero el hombre contesta que no. Después Muhammad trata de asegurarse de que lo que Mā'iz entiende por relación sexual ilícita es realmente un acto en el que ha habido penetración y no otra cosa como un beso, una caricia o un abrazo. Pero Mā'iz confirma que ha existido coito. El Profeta pregunta entonces si ha estado casado, a lo cual el hombre contesta que sí. En ese momento el Profeta ordena que se lo lleven y que lo lapiden ${ }^{62}$.

Lo que hicieron los cuatro hombres a los que se refirió Ibn al-Qāsim, prosigue Ibn Rušd tras citar el hadiz de al-Hazzāl, representa una demanda y una denuncia [contra el hombre] por zinä, convirtiéndose ellos en sus calumniadores. Por tanto, es obligatorio aplicarles el hadd correspondiente, a menos que presenten a cuatro testigos como ellos que hayan presenciado el acto «como el pincel de antimonio en el estuche de antimonio». Pero si fueran miembros de la policía (aṣhāa šuraț), encargados de modificar el mal [sic]... [o sólo] uno de ellos, y lo agarraron, o lo agarró, y lo llevaron [ante las autoridades] y dan testimonio contra él, se aceptará su testimonio porque ellos al atraparlo y denunciarlo [ante las autoridades] hicieron lo que debían. En al-Wädiḥa se transmite a partir de Muṭarrif, Ibn al-Māŷī̌sūn y Aṣbag que si cuatro testigos dan testimonio de zinā contra un hombre, su testimonio será lícito, tanto si llegan todos juntos como si declaran por separado, siempre que el intervalo de tiempo que medie entre sus distintas declaraciones sea corto. Esto quiere decir que si detenerle les estaba permitido, aunque ocultar-

${ }^{60}$ Muwatta', transmisión de Yahyà b. Yahyà, capítulo sobre las sanciones coránicas

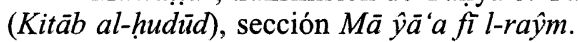

${ }_{61}$ Así lo piensa también M. Haŷŷyì, véase Bayān, XVI, 335 n. 173.

${ }^{62}$ Más detalles en Peters, R., Crime and punishment, capítulo 1, sección 1.6.1. 
lo (al-sitr) hubiera sido preferible, no actuaron como parte contraria (jusama $\bar{a}^{\prime}$ ) [del acusado] pues no denunciaron por interés particular, sino para Dios. En este caso, por tanto, es obligatorio que su testimonio sea aceptado ${ }^{63}$.

Parece pues que Ibn Rušd era contrario al ejercicio voluntario del principio de al-amr bi-l-ma'rüf wa-l-nahy 'an al-munkar, al menos por lo que se refiere a los delitos de $z i n \bar{a}{ }^{64}$. En consecuencia, si la denunciada conseguía que su hijo fuera atribuido a su marido y los que denunciaron a la mujer no formaban parte de la šurța o no tenían cuatro testigos que la hubieran visto cometer zinā, Ibn Rušd hubiera sido partidario de castigarlos con el hadd por calumnia. Y si eran miembros de la policía, le parecía reprobable que la hubieran denunciado.

En otro pasaje de su Bayān ${ }^{65}$ comenta la opinión de Mālik según la cual

\footnotetext{
No conviene (lä yanbagī) que el tutor matrimonial de una mujer que ha cometido zinā informe de ello al hombre que pide su mano. Ibn Rušd afirma que esto no es una recomendación sino que el hombre está obligado (wäŷib 'alay-hi) a ocultar las «indecencias» (fawāhišs) propias y las ajenas, invocando de nuevo el hadiz del Profeta antes citado. Como base textual de su postura Ibn Rušd cita también un pasaje del Muwatța' según el cual el califa 'Umar b. al-Jațāāb castigó con una paliza, o estuvo a punto de hacerlo, a un tutor matrimonial que al negociar el contrato de matrimonio de su hermana, informó al pretendiente de que ella había fornicado (ahdatat). El hecho de haber cometido zinā no se asimila a los defectos que pueden invalidar un contrato de venta y que el vendedor está obligado a declarar.
}

Así pues, Ibn Rušd era partidario de aplicar una doctrina que, si era seguida de forma estricta, reducía considerablemente las posibilidades de que un juez llegara a dictaminar un castigo como la lapidación. Sin embargo y al menos formalmente, Ibn Rušd sostiene la vigencia de esta pena. En ello no se diferencia de la postura sostenida por las escuelas jurídicas sunníes, mientras que los jāriŷ́íes no eran partidarios de aplicar la lapidación en ningún caso ${ }^{66}$. El esfuerzo de autores como Ibn 'Abd al-Barr y Abū Bakr Ibn al-'Arabī ${ }^{67}$ por recopilar las tradiciones

${ }^{63}$ Bayān, XVI, 335-36

${ }^{64}$ Compárese con Cook, M., Commanding Right and Forbidding Wrong in Islamic Thought, Cambridge (RU), Cambridge University Press, 2000, 363-65.

65 IV, 262-63.

66 Aparte de los jāriŷ́ies y de los herejes (ahl al-bida), según Ibn 'Abd al-Barr esta postura la seguían también algunos mu'tazilíes. Véase Istid̄kär, XXIV, 52-3.

${ }_{67}$ El primero en su Istid̄kär y el segundo en su Qabas, III, 1002-1018. También insiste en ello Ibn Hazm en su Muhallà, XI, n. . 2204, 233-38, esp. 236-37. 
en las que se basaba la práctica de la lapidación y la insistencia en que se trataba de una sunna sólida (al-raŷm sunna māḍiya) ${ }^{68}$ parece apuntar a que los jāriyíes no fueron los únicos en rechazar el castigo por no disponer de base textual en el Corán. Entre ellos no debieron de contarse los seguidores de Ibn Hazm, pues para este jurista la opinión de quienes no le ven fundamento a la lapidación ha de ser rechazada porque contradice lo que es firme acerca del Profeta (qawl man lam yara al-raŷm as lan fa-qawl margūb 'an-hu li-anna-hu jiläf al-tābit 'an rasūl Allāh sallà Allāh 'alay-hi wa-sallam) ${ }^{69}$. Abū Bakr Ibn al-'Arabī aporta algunas pistas al comentar el caso de un grupo de beréberes de las montañas de Trípoli ${ }^{70}$ los cuales sostenían que la ablución ritual con agua ( $w u d \bar{u}^{\prime}$ ) era una innovación, que lavarse con arena era el principio legal y que la lapidación era nula, debiendo ser castigado el fornicador con la fustigación hasta la muerte ${ }^{71}$.

Ibn al-Hāâŷy, mālikí de al-Andalus contemporáneo de Ibn Rušd y de Abū Bakr Ibn al-'Arabī, llegaba al extremo de asegurar que

Existe consenso entre los alfaquíes en que aquel que dice que la lapidación no es obligatoria para el muhșan, ha de ser ajusticiado por infiel $\left(k u f r^{a n}\right)$, porque ha rechazado una de las normas legales de Dios $\left(\underline{h u k m^{a n}} \text { min ahkäm Alläh }\right)^{72}$.

68 Véase Ibn al-'Arabī, Qabas, III, 1002.

${ }^{69}$ Ibn Hazm, Muhallà, XI, n. ${ }^{\circ} 2204,234$. Ibn Hazm considera que si un grupo de opositores al poder político se levanta acogiéndose a una interpretación religiosa ( $t a$ 'wīl) que implique negar que quien comete $z i n a \bar{a}$ ha de ser lapidado, dicha interpretación religiosa queda descalificada y quienes la sostengan no podrán arrogarse la categoría legal de rebeldes. Véase Abou El Fadl, Kh., Rebellion \& Violence in Islamic law, Cambridge-U.K., Cambridge University Press, 2001, 212.

${ }^{70} \mathrm{Si}$ examinamos el itinerario del viaje a Oriente de Abū Bakr Ibn al-'Arabī (véase Lucini, M., «Ibn al-'Arabī, Abū Bakr» en Lirola, J. y Puerta, J.M. (dirs.), Enciclopedia de al-Andalus: Diccionario de Autores y Obras Andalusies, I, Sevilla-Granada, 2002, 457-68) pudo tratarse de cualquiera de los dos Trípolis, aunque la mención a las tribus beréberes y a las montañas cercanas parecen indicar que se trata del de Libia. Por otra parte, según las entradas correspondientes en $E I^{2}$, era el Tarābulus al-Garb, el que solía denominarse Țarābulus simplemente, frente a la expresión Ṭarābulus al-Šām, que solía utilizarse para aludir al Trípoli libanés.

71 Qabas, III, 1009. La cuestión del raŷm difiere claramente de las del wudu' y el tayammum en que la primera no tiene base coránica mientras que las otras dos sí. Por otra parte, las aleyas relativas al wudu' y al tayammum apuntan claramente a que la ablución ritual con arena está permitida sólo cuando es imposible hacerla con agua. Véase $E I^{2}$, «Wudu'» [Chaumont, E.] y EI ${ }^{2}$, «Tayammum» (Wensinck, A.J.-[Reinhart, A.K.]. Véase también Averroes, The distinguished Jurist's primer: a translation of Bidayat al-Mujtahid, trad. Khan Nyazee, I.A., revisada por Abdul Rauf, M., Doha, Garnet Publishing Ltd., 1994-2000, 2 vols., I, 523.

${ }_{72}$ Al-Burzulì, Fatāwà, VI, 147-48. 
A lo cual al-Burzulī, transmisor de la noticia, añade lo siguiente:

Si el consenso es firme, que no se tenga en consideración la discrepancia que los jăriŷíes mantienen al respecto, porque son infieles o por la ausencia de estima en que se les tiene ${ }^{73}$.

Es decir, existía el riesgo de que grupos de musulmanes se aferraran a la discrepancia de los jāriŷ́ís para alegar ausencia de consenso $y$, por tanto, de argumento en el que legitimar la práctica de la lapidación. Para disuadir a todos los que fueran receptivos a esta postura, se les asimilaba con los jāriŷíes, los herejes y los infieles y se les amenazaba con la muerte.

Más allá de una mera cuestión de discrepancia legal, manifestarse en contra de la lapidación pudo ser una forma de resistirse a los esfuerzos centralizadores llevados a cabo por los ulemas del período premoderno en aras de la consolidación de una identidad islámica homogénea ${ }^{74}$.

Si la mujer de nuestra fetua consiguió atribuir su hijo al hombre con el que estaba o había estado casada, quedaba entonces el aspecto privado del delito por resolver, es decir, la calumnia de la mujer contra el hombre al que había acusado de violarla y la calumnia de los denunciantes contra la mujer. Surgió entonces la duda de si era posible perdonar al calumniador una vez que el asunto había llegado a conocimiento de las autoridades.

Ibn al-Qāsim opinaba que una vez que el asunto había llegado al sultán, no había posibilidad de perdón. Ibn Rušd matiza esta postura aludiendo a una máxima de Mālik que aparece en la Mudawwana y según la cual la cuestión es como afirma Ibn al-Qāsim, a menos que el calumniado quiera ocultar el asunto [por pudor]

${ }^{73}$ Ibid.

${ }^{74}$ Sobre dichos esfuerzos, véase Berkey, J.P., The Formation of Islam. Religion and Society in the Near East, 600-1800, Cambridge (Reino Unido), Cambridge University Press, 2003, 146-7. Según Berkey, el derecho islámico procuró equilibrar dos imperativos opuestos: la necesidad de una identidad islámica claramente definida y la necesidad de ocuparse de la diversidad de creencias y de prácticas existente dentro de la comunidad. Esto se llevó a cabo de diversas maneras. Una de ellas fue precisamente la doctrina del consenso, la cual resultó esencial en la consolidación de la autoridad de las escuelas legales. Se trataba de una doctrina suficientemente poderosa como para permitir que la comunidad pudiera sancionar principios y prácticas que parecían ir en contra de textos coránicos explícitos. De manera más amplia, la doctrina del $i y \hat{m} \bar{a}^{\prime}$ constituyó el fundamento de la autoridad que los ulemas, y especialmente los juristas, reclamaban sobre la tradición islámica y por tanto, sirvió para reforzar su creciente autoridad social y cultural. 
(illã an yurìda sitr ${ }^{a n}$ ). Ibn Rušd señala que esta cuestión se rige de acuerdo con tres máximas: 1) del $q a d f$ no depende el derecho de Dios altísimo y por tanto, el calumniado puede perdonar a quien le calumnió, aunque el asunto hubiera llegado ya al sultán, por pudor o por otra razón, 2) del qadf depende el derecho de Dios altísimo y por tanto al calumniado no le está permitido perdonar a quien le calumnió, ni antes ni después de que el asunto llegue al sultán, 3) que del qad $f$ no depende el derecho de Dios altísimo hasta que llega al sultán y el calumniado puede perdonar a su calumniador antes de que el asunto llegue al sultán, pero después ya no le está permitido, a menos que quiera ocultar[lo para proteger su reputación] ${ }^{75}$.

El hecho de haber citado la opinión de Mālik inmediatamente después de la de Ibn al-Qāsim indica que la máxima por la que se inclinaba Ibn Rušd era la tercera. Si la mujer era perdonada por el hombre al que había acusado de haberla violado y si ella perdonaba a las personas que la habían denunciado, el asunto quedaba zanjado al menos desde el punto de vista legal.

La posibilidad de que la mujer fuera efectivamente condenada a la lapidación no puede excluirse, sin embargo. Lo que es seguro es que, de momento, no ha sido posible localizar ninguna referencia a la ejecución de lapidaciones en el Occidente islámico premoderno ${ }^{76}$, aunque sí en otras regiones del mundo islámico ${ }^{77}$. Algunos testimonios indican que el delito se castigó también recurriendo a penas distintas de las previstas por la doctrina, como la castración del varón, el ahorcamiento, la muerte en la hoguera e incluso el pago de una multa ${ }^{78}$.

Por otra parte, en la imagen de la práctica judicial que proyectan las colecciones de fetuas del Occidente islámico premoderno los ca-

75 Véase Ibn Rušd, Bayān, XVI, 347-48. Véase también Ibn Abī Zayd al-Qayrawānī, Nawādir, XIV, 368-71.

${ }^{76}$ Véase en este mismo sentido Marín, M., Mujeres en al-Andalus, 674-5.

77 Véanse dos casos en Ibn Tagrī Birdī, Nuŷūm al-zāhira fì mulūk Mișr wa-l-Qāhira, p. 385 y 1619 de la ed. online de www.alwaraq.com, y otro citado por Peters, R., Crime and Punishment, capítulo 2, apartado 1.4.1.

78 Véase Lev, Y., "Aspects of the Egyptian Society in the Fatimid Period», en Vermeulen, U. y Van Steenbergen, J. (eds.), Egypt and Syria in the Fatimid, Ayyubid and Mamluk Eras, Lovaina, 2001, III, 1-31; Berkey, J.P., The Formation of islam, 243; Goitein, S.D., "The sexual mores of the common people» en al-Sayyid Marsot, A.L. (ed.) Society and the sexes in Medieval Islam, Malibu, 1979, 43-61, en 56; Petry, C.F., «Royal justice in Mamlūk Cairo: contrasting motives of two sultāns»» en Marín, M. y García-Arenal, M. (eds.), Saber religioso y poder político en el islam, Madrid, AECI, 1994, 197-211, en 207-10; Peirce, L., Morality tales. Law and Gender in the Ottoman court of Aintab, Berkeley-Los Angeles-Londres, University of California Press, 2003, 319, 322, $330,333$. 
díes aparecen reticentes a aplicar sanciones coránicas ${ }^{79}$. Un claro $-\mathrm{y}$ espectacular - ejemplo de ello lo constituye el proceso contra al-Ḥaskūrī, un jurista fesí que fue acusado de $z i n \bar{a}^{80}$.

\section{Conclusiones}

Es cierto que para un jurista como Ibn Rušd el delito de zinā merece ser tratado con la mayor severidad posible. Sin embargo, la doctrina legal, de cuyo seguimiento estricto también es partidario Ibn Rušd, se «blinda» frente a la aplicación del castigo de zinā de cuatro maneras: 1) imponiendo fuertes restricciones en los medios de prueba, 2) disuadiendo a quienes están dispuestos a testificar con la amenaza de la pena por calumnia, 3) permitiendo al acusado retirar su confesión en cualquier momento 4) sosteniendo la doctrina de «al-walad li-l-firäšs. Aunque no la hacía absolutamente imposible, la propia doctrina legal dificultaba enormemente la posibilidad de que se aplicara la pena prescrita.

Pero para que una doctrina sea aplicada es necesario primero que haya juristas que la conozcan bien, segundo que haya tribunales presididos por un jurista de ese nivel y tercero, que el acusado tenga la posibilidad de comparecer ante un tribunal de ese tipo. En la primera mitad del siglo XII las dos primeras condiciones se cumplían sobradamente. Bajo el gobierno de los almorávides se encuentran activos alfaquíes de la talla de Ibn Rušd al-Ŷadd, Abū Bakr b. al-'Arabī y el cadí 'Iyāọ, tres de las figuras más destacadas de la jurisprudencia mālikí de todos los tiempos. Los tres ejercieron la judicatura en ciudades como Córdoba, Sevilla, Granada y Ceuta. Por otra parte, de una recopilación de casos judiciales del período almorávide relacionados precisamente con la actividad como juez y como muftí de uno de esos personajes, el cadí 'Iyāọ, se desprende una tendencia hacia el segui-

${ }^{79}$ Véase Molina, E., «L'attitude des juristes de al-Andalus en matière de droit pénal. A propòs d'une publication récente sur le thème», Actes du VII Colloque Universitaire Tuniso-Espagnol sur Le patrimoine andalous dans la culture arabe et espagnole, Tunis, 1991, 175-7 y otros ejemplos en mi «The Application of Penal Law in Almoravid Courts» en M.Kh. Masud, R. Peters y D. Powers (eds.), Dispensing Justice in Muslim Courts: Qadis, Procedures, and Judgments, Leiden, Brill (en prensa).

80 Analizado por Powers, D., «From Almohadism to Mālikism: The case of al-Ḥaskūrī, the Mocking Jurist, ca. 712-716/1312-1316». 
miento de las normas de procedimiento penal elaboradas por los juristas de la escuela mālikí. Es cierto que surgían numerosas dudas respecto a su aplicación correcta, dado que estas normas eran distintas de las del procedimiento «civil» y que, además, los juristas sostenían opiniones discrepantes al respecto. No obstante, estos problemas podían ser solucionados sobre la marcha solicitando el dictamen de los expertos, además del de los alfaquíes miembros de la šūrà o consejo consultivo del propio magistrado ${ }^{81}$. De hecho, si conocemos el caso de zinā que he analizado en este artículo es precisamente porque el juez consulta sus dudas con Ibn Rušd.

Respecto a la tercera condición, si, tal como he tratado de mostrar, la principal preocupación de Ibn Rušd es que la acusada compareciera ante el juez supremo es porque para muchas personas el acceso a la justicia religiosa que aplicaban los cadíes no debía de ser fácil, bien porque esa justicia no llegaba a todos los rincones del imperio almorávid, o porque las familias o las comunidades locales «reparaban» por su cuenta las rupturas del código de honor antes de llegaran a conocimiento de las autoridades ${ }^{82}$.

Como hemos visto, Ibn Rušd sostiene la validez de la lapidación como castigo de zinā cuando los acusados son muhșan, pero al mismo tiempo no duda en tomar una posición inequívoca en contra de quienes ponen en conocimiento de las autoridades la comisión de un delito tan grave como el de zina $\bar{a}$, tanto si actúan por cuenta propia como si lo hacen por encargo de la autoridad. Para justificar su postura Ibn Rušd se remonta al modelo de conducta del Profeta y del califa 'Umar. La selección de este modelo, de entre la amplia gama de opciones también sancionadas por la sunna, habla por sí sola de su posición particular frente al delito y sus consecuencias.

Los investigadores han avanzado diversas hipótesis para explicar la actitud contradictoria de los juristas, entre la afirmación de la vigencia de la lapidación y el respeto escrupuloso de unas normas que hacen prácticamente imposible la aplicación efectiva del castigo ${ }^{83}$.

\footnotetext{
81 Ésta es la conclusión a la que llego en mi artículo «The Application of Penal Law in Almoravid Courts».

${ }^{82}$ Lo cual podía y aún puede, aunque no siempre, terminar con la muerte de la mujer acusada del delito. Véase $E P^{2}$, s.v. «'urfi, 2. Arab customary law, II. General features [Stewart, F.H.].

${ }^{83}$ Véase, por ejemplo, Coulson, N.J., «Regulation of sexual behaviour under traditional Islamic Law», 65-6; Johansen, B., «The Claims of Men and the Claims of God:
} 
Los materiales que he analizado en este artículo no nos ayudan a precisar las razones por las cuales las menciones a la emisión y puesta en práctica de sentencias de lapidación son tan escasas para el período pre-moderno. Si bien es cierto que muchos muftíes y jueces se muestran extremadamente cautos e incluso reticentes a la hora de aplicar sanciones coránicas, no es menos cierto que hubo muftíes que dictaminaron a favor de la aplicación del hadd ${ }^{84}$ e individuos anónimos que estuvieron dispuestos a sacar a la luz pública las transgresiones sexuales ajenas, a pesar de las condenas que se expresan con respecto a esta conducta. Sin embargo, la fetua emitida por Ibn Rušd es reveladora acerca de una cuestión importante y es que si interesó mantener el castigo en vigor fue en parte con el fin de resaltar la idea de una jerarquía judicial en la cima de la cual se encontraba el juez religioso con jurisdicción ilimitada ( $q \bar{a} d \underline{̣} \bar{l} l-\hat{y} a m \bar{a}^{\prime} a$ ), cuyas competencias exclusivas no podían ser ejercidas por jueces religiosos de menor categoría y mucho menos por magistrados no religiosos. Y si se insiste en que sólo el cadí supremo está autorizado a dictaminar la aplicación de sanciones coránicas que entrañen la muerte del acusado, se está excluyendo también al gobernante ${ }^{85}$.

\section{RESUMEN}

Partiendo del análisis de una fetua en la que se plantea la posibilidad de condenar a la lapidación a una mujer acusada de haber mantenido relaciones sexuales ilícitas con un hombre, se analiza la doctrina legal sobre zinā de Ibn Rušd el abuelo (m. 520/1126), uno de los juristas mālikíes más relevantes de todos los tiempos. El análisis de esta doctrina conduce a una reflexión acerca de tres cuestiones: 1) la escasez de referencias a la aplicación del castigo de lapidación en el período pre-moderno, 2) la actitud contradictoria de los juristas musulmanes de ese mismo período, los cuales, por una parte sostienen la vigencia del castigo y por otra parte insisten en el respeto escrupuloso de una doctrina que hace que sea prácticamente imposible aplicarlo y 3 ) la vigencia del corpus de opiniones creado por estos juristas en los debates contemporáneos acerca de la práctica de la lapidación.

The Limits of Government authority in Hanafite Law», Pluriformiteit en verdeling van de macht in het midden-oosten, MOI publicatie 4, enero 1980, 84-90; Peirce, L., Morality Tales, 333 y Peters, R., Crime and punishment, capítulo 1, sección 1.6.1.

84 Véase $M i$ 'yăr, II, 430-2 y X, 361-67.

${ }^{85}$ Mientras que, como señala Ch. Müller en su contribución, en Córdoba, durante la época de las taifas, era el soberano quien tomaba personalmente las decisiones acerca de la emisión de sentencias de muerte y de su ejecución y no el jefe de la policía ni el cadí. 


\section{ABSTRACT}

The Maliki jurist Ibn Rushd al-Jadd (d.520/1126) issued a fatwā regarding stoning as a punishment for zinā (unlawful sexual relations). This article examines this fatwa , focusing on three problems: 1) the scarcity of references to implementation of stoning as a punishment for zinā in the pre-modern period, 2) the generally contradictory attitude of pre-modern Muslim jurists, who stressed the validity of stoning as a punishment for zinā but also called for a strict observance of the law, a factor that made it almost impossible to implement, and 3) the importance of the legal opinions offered by pre-modern fuqaha' ' with regard to contemporary discussions on stoning. 